Portland State University

PDXScholar

\title{
Effectiveness of Fuel Treatments for Mitigating Wildfire Risk and Sequestering Forest Carbon: A Case Study in the Lake Tahoe Basin
}

\author{
E. Louise Loudermilk \\ Portland State University \\ Alison Stanton \\ Robert M. Scheller \\ Portland State University, rmschell@pdx.edu \\ Thomas E. Dilts \\ University of Nevada, Reno \\ Peter J. Weisberg \\ University of Nevada, Reno
}

Follow this and additional works at: https://pdxscholar.library.pdx.edu/esm_fac See next page for additional authors

Part of the Environmental Indicators and Impact Assessment Commons, and the Natural Resources Management and Policy Commons

Let us know how access to this document benefits you.

\section{Citation Details}

Loudermilk, E. Louise, et al. "Effectiveness of fuel treatments for mitigating wildfire risk and sequestering forest carbon: A case study in the Lake Tahoe Basin." Forest Ecology and Management 323 (2014): 114-125.

This Article is brought to you for free and open access. It has been accepted for inclusion in Environmental Science and Management Faculty Publications and Presentations by an authorized administrator of PDXScholar. Please contact us if we can make this document more accessible: pdxscholar@pdx.edu. 


\section{Authors}

E. Louise Loudermilk, Alison Stanton, Robert M. Scheller, Thomas E. Dilts, Peter J. Weisberg, Carl Skinner, and Jian Yang

This article is available at PDXScholar: https://pdxscholar.library.pdx.edu/esm_fac/48 


\title{
Effectiveness of fuel treatments for mitigating wildfire risk and sequestering forest carbon: A case study in the Lake Tahoe Basin
}

\author{
E. Louise Loudermilk ${ }^{\mathrm{a}, *}$, Alison Stanton ${ }^{\mathrm{b}, 1}$, Robert M. Scheller ${ }^{\mathrm{a}, 2}$, Thomas E. Dilts ${ }^{\mathrm{c}, 3}$, Peter J. Weisberg ${ }^{\mathrm{c}, 4}$, \\ Carl Skinner ${ }^{\mathrm{d}, 5}$, Jian Yang ${ }^{\mathrm{c}, 3}$
}

${ }^{a}$ Environmental Science and Management Department, Portland State University, PO Box 751, Portland, OR 97207, USA

b 3170 Highway 50 Suite \#7, South Lake Tahoe, CA 96150, USA

' Department of Natural Resources and Environmental Science, University of Nevada, Reno, 1664 N. Virginia St., Mail Stop 186, Reno, NV 89557, USA

${ }^{\mathrm{d}}$ Pacific Southwest Research Station, USDA Forest Service, 3644 Avtech Parkway, Redding, CA 96002, USA

\section{A R T I C L E I N F O}

\section{Article history:}

Received 13 December 2013

Received in revised form 3 March 2014

Accepted 6 March 2014

Available online 31 March 2014

\section{Keywords:}

Fuel treatments

Wildfire

Carbon management

Effectiveness

LANDIS-II

Mixed-conifer

\begin{abstract}
A B S T R A C T
Fuel-reduction treatments are used extensively to reduce wildfire risk and restore forest diversity and function. In the near future, increasing regulation of carbon (C) emissions may force forest managers to balance the use of fuel treatments for reducing wildfire risk against an alternative goal of $C$ sequestration. The objective of this study was to evaluate how long-term fuel treatments mitigate wildfires and affect forest C. For the Lake Tahoe Basin in the central Sierra Nevada, USA, fuel treatment efficiency was explored with a landscape-scale simulation model, LANDIS-II, using five fuel treatment scenarios and two (contemporary and potential future) fire regimes. Treatment scenarios included applying a combination of light (hand) and moderate (mechanical) forest thinning continuously through time and transitioning from these prescriptions to a more mid-seral thinning prescription, both on a 15 and 30 year rotation interval. In the last scenario, fuel treatments were isolated to around the lake shore (nearby urban settlement) to simulate a low investment alternative were future resources may be limited. Results indicated that the forest will remain a $\mathrm{C}$ sink regardless of treatment or fire regime simulated, due to the landscape legacy of historic logging. Achievement of a net $C$ gain required decades with intensive treatment and depended on wildfire activity: Fuel treatments were more effective in a more active fire environment, where the interface between wildfires and treatment areas increased and caused net $C$ gain earlier than as compared to our scenarios with less wildfire activity. Fuel treatments were most effective when continuously applied and strategically placed in high ignition areas. Treatment type and re-application interval were less influential at the landscape scale, but had notable effects on species dynamics within management units. Treatments created more diverse forest conditions by shifting dominance patterns to a more mixed conifer system, with a higher proportion of fire-tolerant species. We demonstrated that a small amount of wildfire on the landscape resulted in significant changes in the $C$ pool, and that strategically placed fuel treatments substantially reduced wildfire risk, increased fire resiliency of the forest, and is beneficial for long-term C management. Implications for landscape management included consideration for prioritization of treatment areas and creating ideal re-entry schedules that meet logistic, safety, and conservation goals. In forests with a concentrated wildland urban interface, fuel treatments may be vital for ensuring human welfare and enhancing forest integrity in a fire-prone future.
\end{abstract}

Published by Elsevier B.V.
* Corresponding author. Present address: Forestry Sciences Laboratory, Center for Forest Disturbance Science, USDA Forest Service, 320 Green Street, Athens, GA 30602, USA. Tel.: +1 7065594309.

E-mail addresses: elloudermilk@fs.fed.us (E.L. Loudermilk), alisonestanton @gmail.com (A. Stanton), rmschell@pdx.edu (R.M. Scheller), tdilts@cabnr.unr.edu (T.E. Dilts), pweisberg@cabnr.unr.edu (P.J. Weisberg), cskinner@fs.fed.us (C. Skinner), jyang@cabnr.unr.edu (J. Yang).

1 Tel.: +1 4159902269 .

2 Tel.: +1 5037252497 .

3 Tel.: +1 7757846984

4 Tel.: +1 7757847573 .

5 Tel.: +1 5302262554 .

\section{Introduction}

Fuel-reduction (i.e., forest thinning) treatments are used extensively throughout the western US and worldwide to reduce hazardous surface and ladder fuels and restore forest structure to more fire resilient conditions (Agee and Skinner, 2005). The forests of the Sierra Nevada are of particular concern because fuel loads and density of small trees have exceeded known historic conditions (Parsons and DeBenedetti, 1979) and the wildland urban interface has increased (Radeloff et al., 2005; Syphard 
et al., 2007). As a result, recent severe wildfires often exceed estimates of historic severity (Westerling et al., 2006; Littell et al., 2009) and have destroyed homes and businesses and threatened urban centers (Radeloff et al., 2005; Safford et al., 2009). Applying fuel treatments has become an essential management tool for reducing wildfire intensity and severity in this region (Agee and Skinner, 2005; Schwilk et al., 2009; Syphard et al., 2011). The trade-offs among fuel treatments, labor costs to implement them, preserving wildlife habitat, and in the near future, regulation of carbon (C) emissions, are of concern (Calkin and Gebert, 2006; Pilliod et al., 2006; Scheller et al., 2011b; Campbell et al., 2012).

In particular, regulation of $C$ emissions may force forest managers to balance the use of fuel treatments for reducing wildfire risk against goals to maintain or increase $C$ sequestration (Hurteau et al., 2008). This will require consideration of the net balance between the immediate loss of $\mathrm{C}$ from live and detrital matter during fuels management (e.g., mechanical thinning and prescribed burning) against the long-term $\mathrm{C}$ sequestration potential associated with reduced $\mathrm{C}$ emissions from lower intensity wildfires (Hurteau et al., 2008; Scheller et al., 2011a). Previous research that explicitly study $C$ dynamics have typically addressed only aboveground $C$ stocks (e.g., Hurteau and North, 2009), although surface and soil C are important long-term C stocks as well (Johnson et al., 1997) and fluctuate in response to changes in live and detrital inputs (Scheller et al., 2011a; Karam et al., 2013). Although much of the live $C$ during a severe wildfire is emitted, a portion is transferred to the detrital pool as coarse woody debris and surface $\mathrm{C}$, and eventually to the soil C pools (Scheller et al., 2011a; Karam et al., 2013). The physical removal of $C$ during thinning and how debris is handled after thinning (e.g., pile or prescribed burning) may influence these C flows as well (Murphy et al., 2006; Finkral and Evans, 2008; Hurteau et al., 2008; Nave et al., 2010), but only to the extent of area being treated and re-application interval. This study addresses above and belowground live $C$ as well as soil and detrital $C$ that when combined with effects from wildfire disturbance and forest thinning provide a more complete picture of $C$ dynamics that influence sequestration patterns.

Properly balancing multiple landscape management objectives, including activity implementation (e.g., treatment location) and understanding feedbacks with ecosystem C dynamics (e.g., Daugherty and Fried, 2007; Rhodes and Baker, 2008; Schmidt et al., 2008), requires more information about their inherent trade-offs, and improved awareness of the opportunities for optimizing management at the landscape scale (Syphard et al., 2011). The strategic placement of fuel treatments is important for reducing landscape level wildfire spread and intensity (Finney et al., 2008; Schmidt et al., 2008) and therefore understanding where treatments may be most effective may be more important than the amount of area treated. For instance, wildfire-treatment intersection may be more likely if treatments are applied in areas of known high ignition potential (Thompson et al., 2013). The re-application timeline or rotation period is also of interest because more intensive treatments (e.g., mechanical vs. hand thinning) may have a longer effective period for reducing wildfire risk (e.g., Stephens et al., 2012b). Maintaining fuel treatments through time re-structures the landscape, creating a more fire-resistant forest, and maintains live $\mathrm{C}$ stocks by reducing $\mathrm{C}$ emissions from wildfire in the long run (Hurteau and North, 2009; North and Hurteau, 2011). Estimating the potential for a particular fuel treatment practice or regime to reduce wildfire risk or severity and alter ecosystem and $C$ dynamics requires an assessment at the landscape level where the spatial arrangement of fuel treatments and the potential intersection with wildfires can be addressed (Syphard et al., 2011).

The objective of this study was to evaluate how long-term fuel treatments mitigate wildfires and affect forest $C$ in the Lake Tahoe Basin, a conifer-dominated forest in the central Sierra Nevada, USA, that has experienced fire exclusion over the past 150 years (Beaty and Taylor, 2008).We used a landscape-scale simulation model of forest succession (Scheller et al., 2007), stochastic wildfire (Sturtevant et al., 2009), ecosystem C dynamics (Scheller et al., 2011a), and forest thinning (Syphard et al., 2011) to understand long-term effects of fuel treatments on wildfires, above and belowground C dynamics, as well as species and community structure. A multiple fuel treatment scenario design was used to examine the interactive effects of treatment application in terms of spatial arrangement and location, rotation period, and prescription type. We explored the effectiveness of fuel treatments using two fire regimes that contrast the contemporary fire regime with a more active fire environment that is forecast for the near future. Results are discussed in terms of long-term landscape implementation of fuel treatments and evaluating the potential for net $C$ gain.

\section{Methods}

\subsection{Study area}

Our study area comprises approximately 85,000 ha of forested land in the Lake Tahoe Basin (LTB, Fig. 1). The climate is Mediterranean with a summer drought period; the basin topography and elevation range (ca. 1897-3320 m) control local temperature and precipitation patterns. Mean daily temperatures range from -6 to $24^{\circ} \mathrm{C}$ and have an annual average temperature of $5{ }^{\circ} \mathrm{C}$. Snowfall is the primary form of precipitation (50-150 cm annually), which occurs between October and May and snowpack persists into the summer dependent on elevation. Soils are classified as shallow Entisols or Inceptisols and the more developed soils are Alfisols. The substrate is mainly granite with ancient volcanic bedrock lining the north shore (Rogers, 1974). Tree species distribution in the LTB is controlled by elevation and precipitation (Barbour et al., 2002). The lower montane zone in the west Basin is primarily a mixed conifer forest consisting of up to six co-dominant species including white and red fir (Abies concolor, Abies magnifica A. Murr.), incense cedar (Calocedrus decurrens Torr.), and Jeffrey, sugar, and lodgepole pine (Pinus jeffreyi Grev. \& Balf., Pinus lambertiana Dougl., Pinus contorta Dougl. ex. Loud.). The east side montane zone is dominated by Jeffrey pine, red fir, and/or white fir. The subalpine zone consists of whitebark pine (Pinus albicaulis Engelm.), western white pine (Pinus monticola. Dougl. ex D. Don), and mountain hemlock (Tsuga mertensiana (Bong.) Carr.).

Approximately two-thirds of the lower montane zone in the LTB was clearcut during the Comstock logging era beginning around 1870 and continuing through the beginning of the last century. Timber harvest and subsequent fire suppression has shifted forest age and size distribution from a characteristic old-growth canopy, with an open mid-story, to a denser forest of younger age-cohorts ( $<120$ years old) and more closed mid-story (Barbour et al., 2002; Taylor, 2004).This shift has allowed surface and ladder forest fuels to accumulate and has increased wildfire risk (Beaty and Taylor, 2008). In addition, shade tolerant trees (e.g., white fir and incense cedar) have increased disproportionately over fire-adapted species like Jeffrey and sugar pine (Nagel and Taylor, 2005).

\subsection{Model description and development}

To address the disturbance feedbacks of fuel treatments and wildfires on coarse-scale forest and $C$ dynamics, we used the Landscape Disturbance and Succession model, LANDIS-II (v.6.0). The LANDIS-II model has been used extensively for understanding ecosystem C dynamics (Scheller et al., 2011a, 2011c) and feedbacks associated with wildfire (Sturtevant et al., 2009) and fuel treatments (Syphard et al., 2011). LANDIS-II offers the flexibility 


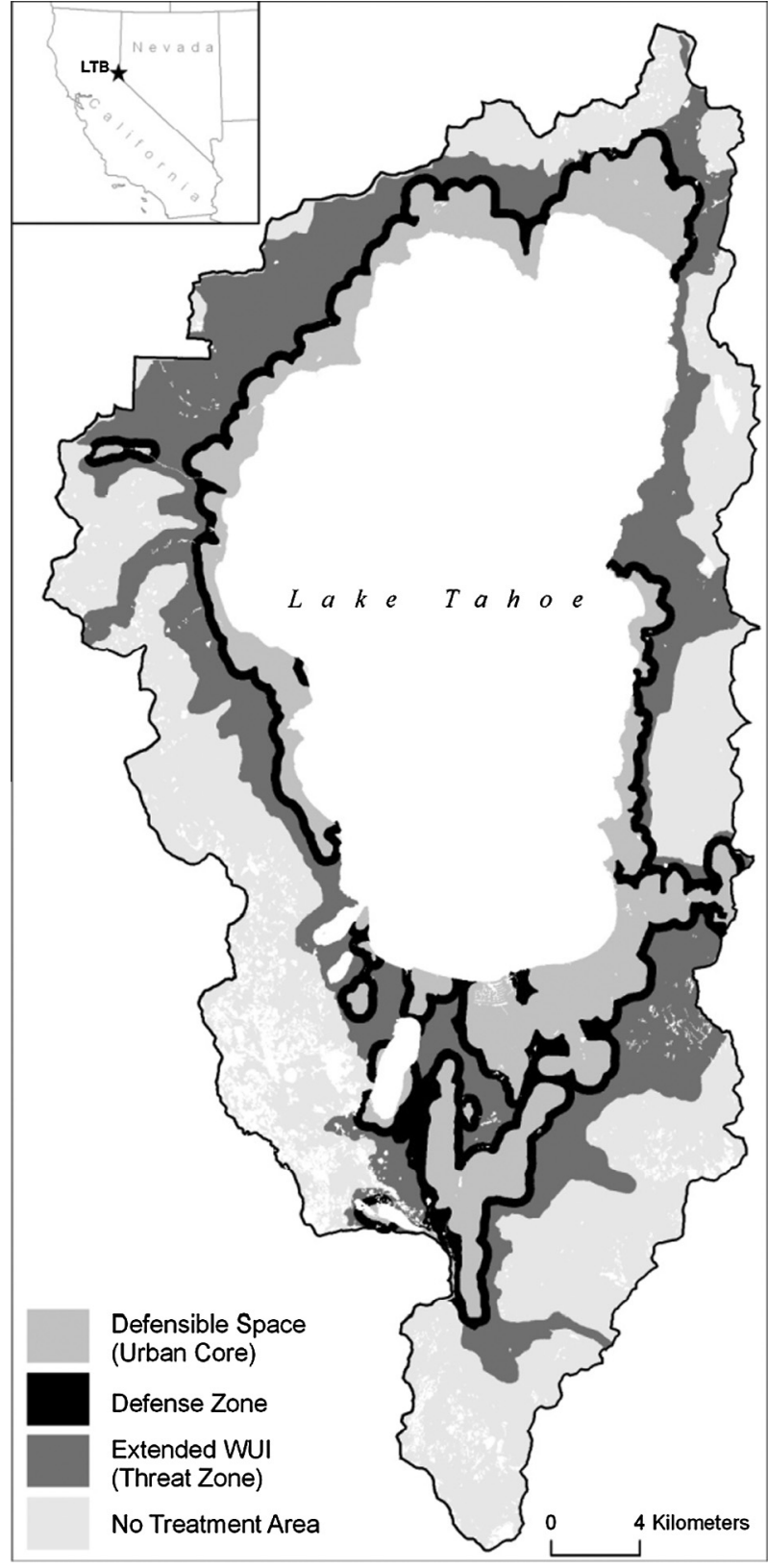

Fig. 1. The study area, the Lake Tahoe Basin, CA, NV, including the fuel treatment management areas designated by LTB managers. Non-modeled areas (white) included any water bodies, rocky outcrops, urban areas, or outside LTB managed boundaries.

to integrate various ecosystem processes and disturbances that interact across large spatial extents and long time periods, ideal for projecting forest succession and responses to human and natural disturbance. The landscape $C$, wildfire, and tree species inputs, parameters, and calibration for the LTB are described in Loudermilk et al. (2013).

\subsubsection{C dynamics}

Ecosystem C dynamics were modeled using the LANDIS-II Century Succession extension (Scheller et al., 2011a), based on the original CENTURY soil model (Parton et al., 1983). This extension (hereon called 'Century') integrates aboveground processes of successional dynamics with $C$ and nitrogen cycling as well as soil decomposition and accumulation; all ecosystem processes are influenced by temperature and precipitation at a monthly time step. Century parameters were developed for three ecosystem levels: tree species, tree functional groups, and ecoregions. Six target model outputs were chosen to calibrate and validate Century parameters based on available literature on the regional estimations and expert opinion. These include aboveground live biomass, soil organic carbon (SOC), soil inorganic nitrogen (mineral $\mathrm{N}$ ), aboveground net primary productivity (ANPP), Net Primary Production (NPP), and Net Ecosystem Production (NEP). Further details on these target model outputs, other parameter descriptions, and examples of calibration procedures for Century are found elsewhere (Scheller et al., 2011a, 2011c; Loudermilk et al., 2013).

\subsubsection{Wildfire regime and fuels}

The Dynamic Fire and Fuels extension (hereon called 'Dynamic Fire') simulated fire behavior and fire effects and was parameterized to reflect local fire regimes. Fire behavior (rate of spread and direction and severity) is a function of fuel type, weather, topography, and ignition rate (Sturtevant et al., 2009). To determine mortality, Dynamic Fire estimates crown fraction burned using a combination of rate of spread, fine foliar moisture content, and fuel-type specific parameters, which is used as an indicator of fire intensity (Sturtevant et al., 2009). Fire severity (i.e., cohorts killed vs. survived) depends on the tree species present and their relative susceptibility to fire. Simulated fire severity is recorded as an integer index ranging from 1 (least severe) to 5 (most severe).

The LTB was divided into three fire regions (Fig. S1), representing distinct fire regime characteristics that determined the expected fire regime (particularly ignition rates) on the landscape. The fire region map was reclassified from a continuous fire ignition density image that was estimated using a spatial point pattern modeling approach from a historical fire occurrence database (Yang et al., 2007; Loudermilk et al., 2013). The three fire regions represented a) South Lake Tahoe urban areas and some lower elevation areas around the lake shore (9603 ha), b) low-to-mid elevation forested area (28,777 ha), and c) high elevation forested areas (31,194 ha). Fires that start in one region may spread to an adjacent region. Fire frequency and size for each region were parameterized and calibrated based on the contemporary fire regime and daily fire weather (see Loudermilk et al., 2013). We only simulated fires $>1$ ha, a threshold often used to remove extremely small fires in the analysis that otherwise contribute little in total area burned and wildfire risk assessment (Miranda et al., 2012). A second 'high' fire regime was created to simulate potential increases in wildfire activity that have recently occurred in the LTB (Safford et al., 2009) and may continue because of changes in climate (Loudermilk et al., 2013) and altered ignition patterns (Loudermilk et al., 2012). The 'high' fire regime was created by doubling the ignition values (3-6 ignitions $\mathrm{yr}^{-1}$ ) from the contemporary values. All other input fire parameters were identical between simulated fire regimes (Table S1).

The Dynamic Fire extension was used to assign fuel types (also see Section 2.3.1) for each active site according to cohort biomass, cohort age, recent conifer mortality (e.g., from fire disturbance), and post disturbance information (Syphard et al., 2011). We used fuel types similar to those already created for the southern Sierra Nevada (Syphard et al., 2011). Each fuel type determines fire behavior and represents fuel bed and ladder fuels conditions with unique fire spread parameters, ignition probabilities, and crown base heights (Sturtevant et al., 2009). Fuel types are dynamic, meaning they are re-classified every time step depending on succession, disturbance, or management activity.

\subsubsection{Forested landscape}

LANDIS-II simulates the life history characteristics of individual species of trees and shrubs, each represented as age-cohorts. Individual trees are not modeled. To characterize initial forest 
communities, we utilized a database and a map of age-cohorts of trees and shrubs developed for the LTB based on the Fuel Characteristic Classification System (FCCS, http://www.fs.fed.us/psw/ partnerships/tahoescience/fccs.shtml) and the existing vegetation map (CALVEG) from the GIS Clearinghouse of the Pacific Southwest Region (http://www.fs.fed.us/r5/rsl/clearinghouse/aa-ref-tmu. shtml) (Ottmar and Safford, 2011). We used data on the 10 most abundant tree species found within the LTB, each represented in our model by unique life history characteristics (i.e., evolutionary strategy) including longevity, age of maturity, shade tolerance, fire tolerance, and sexual and vegetative reproductive capabilities (Table 1). For simplicity, the shrubs were grouped into four functional groups: (1) non-nitrogen fixing re-sprouters, (2) nonnitrogen fixing obligate seeders, (3) nitrogen fixing re-sprouters, and (4) nitrogen fixing obligate seeders. The resulting forest community map was coupled with Forest Inventory Analysis data from the Basin and nearby Sierra Nevada forests to provide ground estimates of species composition and age distribution by forest type (e.g., mixed conifer), similar to (Syphard et al., 2011). The resulting map (Fig. S2) was refined to account for the largest and most significant wildfires from years 2002 to 2010, where canopy tree mortality rates were considerable (up to $100 \%$, Safford et al., 2009; Loudermilk et al., 2013).

\subsection{Fuel treatment development and implementation}

Fuel treatment (i.e., forest thinning) prescriptions and scenarios were developed using an expert-knowledge approach similar to Syphard et al. (2011) and (Collins et al., 2010), where agency personnel at the federal, state, and local level provided information on fuel treatment implementation and tactics, including treatment efficacy. From these communications, we developed fuel treatment strategies that represented their current and anticipated management activities in the LTB at the stand to landscape level.

Fuel treatments were simulated using the Leaf Biomass Harvest extension (v. 2.0.1) of LANDIS-II, that has been successfully used in other fuel treatment (Scheller et al., 2011b; Syphard et al., 2011) and forest harvesting studies (Scheller et al., 2011a). The Leaf Biomass Harvest extension was designed specifically to link with Century to simulate removal of aboveground live leaf and woody biomass of designated species age-cohorts within selected areas and with Dynamic Fire to simulate post-treatment effects on fire behavior and subsequent fire effects. Similar to Syphard et al. (2011), we used this extension to simulate forest thinning from below (i.e., fuel treatments), where much of the older cohort biomass was left intact.

\subsubsection{Fuel treatment prescriptions}

Simulated fuel treatments represented the basic prescriptions deployed in the LTB including hand and mechanical thinning of understory and mid-story trees up to specified diameter limits. Treatments targeted six of the 10 tree species and all shrub functional groups for thinning including white fir, red fir, Jeffrey pine, lodgepole pine, incense cedar, and sugar pine. Aspen is considered a conservation species in the LTB and whitebark pine, western white pine, and mountain hemlock are restricted to high elevations that do not receive fuel treatments. The tree species targeted for thinning were categorized into three removal groups based on management restoration and conservation goals. Greater proportions of the more shade-tolerant and fire-sensitive species (white fir and incense cedar: group 1) were removed preferentially compared to Jeffrey pine, red fir, and lodgepole pine (group 2). Sugar pine (group 3) was grouped separately to minimize removal as much as possible because it is a management goal to promote its distribution and growth in the LTB (Maloney et al., 2011). All shrub functional groups were treated to emulate mortality from thinning operations and subsequent regeneration and re-sprouting. Fuel types were ranked according to their prescription type (Table 2).

2.3.1.1. Light thinning. The light thinning prescription (Syphard et al., 2011) was designed to represent hand-thinning of understory and mid-story trees up to $14 \mathrm{in} .(35.6 \mathrm{~cm})$ in diameter. To simulate realistic thinning operations, thinning was distributed across the youngest age-cohorts (of small trees up to $14 \mathrm{in.} \mathrm{in}$ diameter), removing a successively greater proportion of the very youngest cohorts (Fig. S4). From a fire hazard stand point, this represents reducing ladder fuels and associated fuel loads. This treatment prescription was defined as having a resulting canopy base height of $4 \mathrm{~m}$, was effective for 10 years, and removed $85 \%$ of downed woody debris and $95 \%$ of leaf litter.

2.3.1.2. Moderate thinning. The moderate thinning prescription (Syphard et al., 2011) was designed to represent a more intense mechanical thinning of understory and mid-story trees up to 30

Table 1

Tree species and functional group attributes used in LANDIS-II modeling of the Lake Tahoe Basin, CA, NV, USA.

\begin{tabular}{|c|c|c|c|c|c|c|c|c|c|c|}
\hline Species or functional group & $\begin{array}{l}\text { Longevity } \\
\text { (yrs.) }\end{array}$ & $\begin{array}{l}\text { Age of } \\
\text { sexual } \\
\text { maturity } \\
\text { (yrs.) }\end{array}$ & $\begin{array}{l}\text { Shade } \\
\text { tolerance } \\
(1-5)\end{array}$ & $\begin{array}{l}\text { Fire } \\
\text { tolerance } \\
(1-5)\end{array}$ & $\begin{array}{l}\text { Effective } \\
\text { seeding } \\
\text { distance } \\
(\mathrm{m})\end{array}$ & $\begin{array}{l}\text { Maximum } \\
\text { seeding } \\
\text { distance } \\
(\mathrm{m})\end{array}$ & $\begin{array}{l}\text { Vegetative } \\
\text { reproduction } \\
\text { probability }\end{array}$ & $\begin{array}{l}\text { Minimum } \\
\text { resprouting } \\
\text { age }\end{array}$ & $\begin{array}{l}\text { Maximum } \\
\text { resprouting } \\
\text { age }\end{array}$ & $\begin{array}{l}\text { Post-fire } \\
\text { reprouting } \\
\text { ability }\end{array}$ \\
\hline Pinus jeffreyi & 500 & 25 & 2 & 5 & 50 & 300 & 0 & 0 & 0 & $\mathrm{~N}$ \\
\hline Pinus lambertiana & 550 & 20 & 3 & 5 & 30 & 400 & 0 & 0 & 0 & $\mathrm{~N}$ \\
\hline Calocedrus decurrens & 500 & 30 & 4 & 5 & 30 & 2000 & 0 & 0 & 0 & $\mathrm{~N}$ \\
\hline Abies concolor & 450 & 35 & 4 & 3 & 30 & 500 & 0 & 0 & 0 & $\mathrm{~N}$ \\
\hline Abies magnifica & 500 & 40 & 3 & 4 & 30 & 500 & 0 & 0 & 0 & $\mathrm{~N}$ \\
\hline Pinus contorta & 250 & 7 & 1 & 2 & 30 & 300 & 0 & 0 & 0 & $\mathrm{~N}$ \\
\hline Pinus monticola & 550 & 18 & 3 & 4 & 30 & 800 & 0 & 0 & 0 & $\mathrm{~N}$ \\
\hline Tsuga mertensiana & 800 & 20 & 5 & 1 & 30 & 800 & 0.0005 & 100 & 800 & $\mathrm{~N}$ \\
\hline Pinus albicaulis & 900 & 30 & 3 & 2 & 30 & 5000 & 0.0001 & 100 & 900 & $\mathrm{~N}$ \\
\hline Populus tremuloides & 175 & 15 & 1 & 2 & 30 & 1000 & 0.9 & 1 & 175 & $\mathrm{Y}$ \\
\hline $\begin{array}{l}\text { Non N-fixing resprouting } \\
\text { shrubs }\end{array}$ & 80 & 5 & 2 & 1 & 30 & 550 & 0.85 & 5 & 70 & $\mathrm{Y}$ \\
\hline $\begin{array}{l}\text { Non } \mathrm{N} \text {-fixing obligate seeding } \\
\text { shrubs }\end{array}$ & 80 & 5 & 2 & 1 & 30 & 1000 & 0 & 0 & 0 & $\mathrm{~N}$ \\
\hline $\mathrm{N}-$ fixing resprouting shrubs & 80 & 5 & 1 & 1 & 30 & 500 & 0.75 & 5 & 70 & Y \\
\hline $\begin{array}{l}\text { N-fixing obligate seeding } \\
\text { shrubs }\end{array}$ & 80 & 5 & 1 & 1 & 30 & 800 & 0 & 0 & 0 & $\mathrm{~N}$ \\
\hline
\end{tabular}


Table 2

Fuel type ranking by prescription and fuel type, including descriptions of fuel types. Fuel type rank number was developed from the initial rate of spread $\left(\mathrm{m} \mathrm{min}^{-1}\right)$ at an initial spread index of 35, see Syphard et al. (2011).

\begin{tabular}{|c|c|c|}
\hline Fuel type rank & Fuel types & Description \\
\hline \multicolumn{3}{|c|}{ Light and moderate thinning prescription } \\
\hline 55 & $1,2,4,7,13,16,17,18$ & $\begin{array}{l}\text { Young, mid-aged stands of each forest } \\
\text { type (mixed conifer, pine/white fir, red } \\
\text { fir, and lodgepole) and pure shrub } \\
\text { stands of all ages }\end{array}$ \\
\hline 55 & 8,9 & Mid and old red fir \\
\hline 38 & 15 & Old lodgepole \\
\hline 36 & 5,6 & Mid and old pine/white fir \\
\hline 24 & 3 & Old mixed conifer \\
\hline 14 & 19,20 & Young and old Aspen \\
\hline 12 & 14,90 & $\begin{array}{l}\text { Mid-aged lodgepole, and light } \\
\text { thinning, mid-seral thinning }\end{array}$ \\
\hline 4 & 91 & Moderate thinning \\
\hline \multicolumn{3}{|c|}{ Mid-seral thinning prescription } \\
\hline 75 & $2,5,8,14,17$ & Mid-aged conifers \\
\hline 55 & $1,4,7,13,16,18$ & $\begin{array}{l}\text { Young stands of each forest type } \\
\text { (mixed conifer, pine/white fir, red fir, } \\
\text { and lodgepole) and pure shrub stands } \\
\text { of all ages }\end{array}$ \\
\hline 55 & 9 & Old red fir \\
\hline 38 & 15 & Old lodgepole \\
\hline 36 & 6 & Old pine/white fir \\
\hline 24 & 3 & Old mixed conifer \\
\hline 14 & 19,20 & Young and old Aspen \\
\hline 12 & 90 & Light thinning, mid-seral thinning \\
\hline 4 & 91 & Moderate thinning \\
\hline
\end{tabular}

in. $(76.2 \mathrm{~cm})$ in diameter. This treatment prescription was defined as having a resulting canopy base height of $6 \mathrm{~m}$, and because of the more extensive biomass removal, was effective for 15 years. The prescription removed $75 \%$ of downed woody debris and $90 \%$ of leaf litter. The same species groups were used for mechanical thinning (Fig. S5), but a greater proportion of the smaller age-cohorts (of small and medium trees up to 30 in. diameter) were removed. For comparison, the moderate thinning removed about 20\% more biomass than the light thinning. As mechanical treatments cannot be performed on slopes $>30 \%$, the moderate and light thinning prescriptions were proportionally distributed within each management area based on the amount of area with slope $>30 \%$. The moderate thinning prescription was restricted to $52 \%, 25 \%$, and $16 \%$ area within the defensible space, defense zone, and extended WUI, respectively (see Section 2.3.2, Fig. 1).

2.3.1.3. Mid-seral thinning. The mid-seral thinning prescription was developed with an overall goal of promoting more old-growth characteristics across the landscape (Brown et al., 2004), and was designed as a prospective prescription that may be employed gradually after the initial round of treatments. The prescription was a modification of the light thinning prescription (i.e., 14 in. limit) that targets thinning of mid-seral stage trees (Fig. S6). To continue with restoration efforts and reduction of ladder fuels, younger cohorts of removal group 1 (white fir, incense cedar) were thinned identically as the light thinning approach. The mid-seral thinning prescription used the fire hazard stand selection method to choose stands based on their mid-seral stand structure and composition, rather than fire hazard alone. More specifically, fuel types were ranked (see Section 2.3.2) so both fire hazard and canopy structure (mid-seral dominance) were taken into account when selecting stands for treatment (Table 2).

Each fuel treatment prescription was calibrated to represent how on-the-ground fuel treatments influence fire behavior at the scale modeled. These calibrations required two model assumptions: (1) each thinning prescription included complete removal of targeted biomass percentage (Figs. S4-S6), including any posttreatment activity such as pile burning or prescribed burning; and (2) treatments reduced fire spread potential for 10-15 years, depending on prescription. We tested the second assumption by varying this effective treatment period between 5,10 , and 15 years. Little to no difference was found in area burned between these time periods because of the continuous application of fuel treatments in high wildfire risk areas.

\subsubsection{Fuel treatment area and selection approach}

Fuel treatments were simulated within three designated treatment areas (Marlow et al., 2007): the defensible space, defense zone, and extended wildland urban interface (WUI, Fig. 1). These were generally defined by their proximity to urban areas, structures, or roadways that follow an elevation gradient. The defensible space (10,768 ha, $16 \%$ of total forested area in the LTB) had the highest priority in treatment intensity and application through time. Only the forested portion of this treatment area was simulated; true urban areas (structures, parking lots, roads) were treated as non-active sites. The defense zone ( 8245 ha, $12 \%$ of total forested area) was defined as a $0.40 \mathrm{~km}(0.25$ mile) buffer from the edge of the defensible space, representing an area close but not in direct contact with the urban center of the LTB. The extended WUI $(20,473 \mathrm{ha}, 30 \%$ of total forested area) was defined as a $2.01 \mathrm{~km}$ ( 1.25 mile) buffer from the defensible space, including highway routes into the basin. The remaining portion (43\%) was designated as a non-treatment area, where wildfire risk was low, access was difficult, forest communities were protected, or the area was either designated Wilderness or far in proximity to urban structures and high anthropogenic activity sites.

These treatment areas were further divided into treatment stands, representing an area that was completely treated if chosen based on selection criteria (described below) and treatment interval. To create an inclusive landscape of stands (within treatment areas), a Thiessen polygon technique was used to create a continuous landscape of treatment stands based on the size distribution of recorded treatment activity within each treatment area (Fig. S3, Loudermilk et al., 2012).

Stands were selected for treatment based on estimated "fire hazard". The "fire hazard" stand selection method (found in v. 2.1.1 of the Base Harvest extension) was created based on a management approach of stand selection that assesses forest and fuel characteristics that describe a stand's latent wildfire risk. Site level fuel types were ranked and averaged across a stand within each treatment area (e.g., defensible space), and treated in order of fire hazard (highest first) until the predetermined target area to treat was achieved. Target area was based on rotation period (Gustafson et al., 2000) and described below (see Section 2.3.3). In addition, stands with particular criteria were restricted from treatment. Stands were not treated if quaking aspen (a LTB species of conservation concern) was present in $>30 \%$ portion of the stand area. Furthermore, stands were not treated if they had been treated or burned within the previous 10 years of the simulation.

\subsubsection{Fuel treatment scenarios}

Fuel treatment scenarios were designed to assess how fuel treatment rotation period, prescription type, and spatial extent through time would affect the fire regime, forest composition and structure, as well as carbon stores and fluxes across the landscape. Under all scenarios, initial treatments were simulated in all three treatment areas (defensible space, defense zone, extended WUI) during the first 15 years to emulate the initial treatment period currently being implemented within the LTB under guidance of a region-wide strategy (Marlow et al., 2007). All scenarios also included continual treatments in the defensible space on a 15 year rotation period, since that is where the vast majority of wildfires 
start and the priority to reduce wildfire risk around human communities and infrastructure are not expected to diminish. The following scenario descriptions pertain to treatments simulated in the defense zone and extended WUI after the initial treatment period. The fire hazard stand selection method was used for all scenarios.

Fuel treatment scenarios of varying prescription types were implemented on a 15 and 30 year rotation period. A 'Continued Intensity' scenario was designed to apply fuel treatments on a designated rotation period continuously through time. After the initial treatment period, this scenario was evaluated on a 15 (Fig. 2a) and a 30 year rotation period (Fig. 2 b). Only the light and moderate thinning prescriptions were used for this scenario. A 'Transition to Forest Health Initiative' scenario was designed to transition from the light and moderate thinning prescriptions (after the initial treatment period) to the mid-seral thinning prescription by year 50, using a 15 (Fig. 2c) and 30 year (Fig. 2d) rotation period. This scenario represented a prospective approach to forest thinning that both maintains low fire hazard conditions and promotes oldgrowth structure. Finally, a 'Long Term Urban Core' scenario was designed to exclude additional fuel treatments in the defense zone and extended WUI after the initial treatment period. This scenario was created to investigate a low investment alternative were future resources may be limited and treatment maintenance across all management areas may not be feasible. Here, fuel treatments were maintained on a 15 year rotation period only in the defensible space. For all scenario combinations ( 5 total), five replicates were simulated over 100 years (2010-2110). Only the continuous intensity scenarios were used under the high fire regime simulations.

\section{Results}

\subsection{Fuel treatment effects on wildfires}

Under the contemporary fire regime scenario, treating all three management areas under a 15 or 30 year rotation period (RP) more than doubled the fire rotation period (FRP) and cut fire size in half compared to simulations without fuel treatments (Table 3). Continuous fuel treatments under a 15 or 30 year RP resulted in a $55 \%$ and $47 \%$ increase in mean FRP, respectively. Transition fuel treatments under a 15 or 30 year RP resulted in a $50 \%$ and $49 \%$ increase in mean FRP, respectively. There were no distinct differences between the "transition" and "continuous" fuel treatment scenarios on mean FRP or fire size. Compared to no fuel treatment, the long-term urban core scenario increased the FRP for the LTB by $29 \%$ ( $360-510$ years) and decreased mean annual area burned by $31 \%$ (Table 3).

The reduction in area burned due to fuel treatments was most evident within each of the three management areas (Fig. 3) with similar results for potential fire severity (data not shown, but see Loudermilk et al., 2012). Treatment rotation period ( 15 or 30 years) had little apparent effect at this scale (Table 3). The long-term urban core scenario reduced area burned in the defensible space as intended by the prescription, and this effect also extended into the defense zone, where a reduction in area burned was observed across years compared to untreated areas (Fig. 3). This effect did not range into the extended WUI or outside the treatment area. The long term urban core scenario did not significantly reduce the fire severity index outside the defensible space indicating that the moderating effect on fire spread was due to targeting fuel
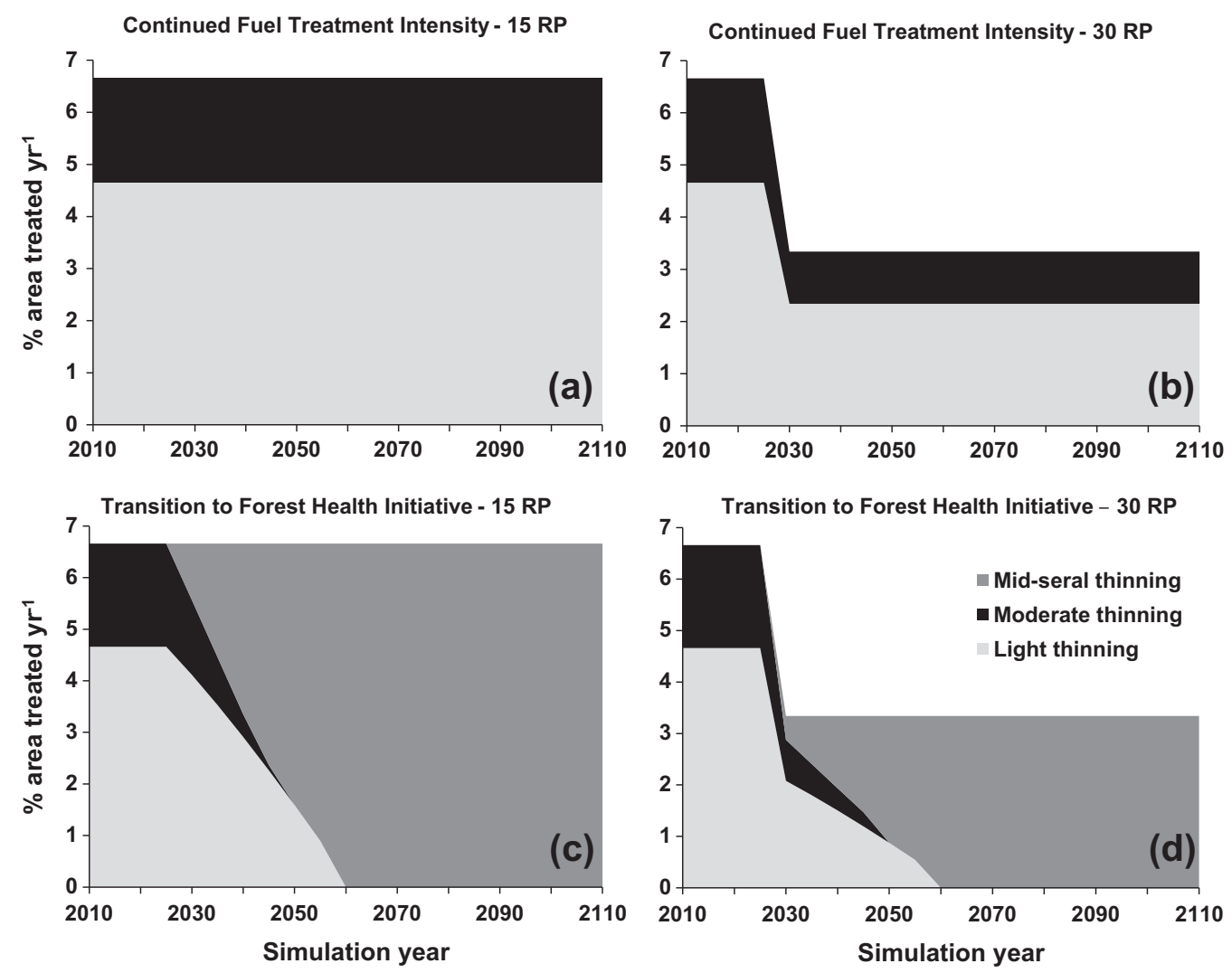

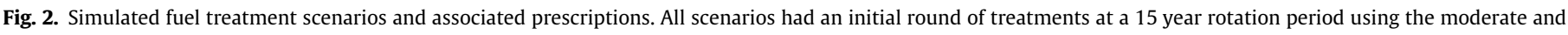

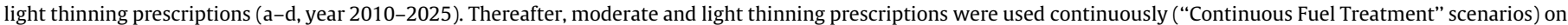

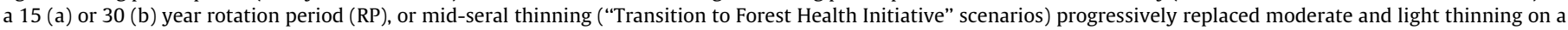
15 (c) or 30 (d) year RP. See text for 'Long Term Urban Core' scenario. 
treatments in high wildfire risk areas rather than residual structural changes to the forest.

Under a no fuel treatment scenario, the simulated high fire regime nearly doubled the mean annual area burned and caused a $48 \%$ reduction in the mean FRP from 360 years to 188 years (Table 3). Applying fuel treatments at a 15 and 30 year rotation period illustrated comparable increases in mean FRP (49\% and $39 \%$, respectively) as simulated for the contemporary fire regime under current climate. Applying fuel treatments at 15 year RP in the high fire regime created a FRP (367 years) similar to that of the contemporary fire regime with no fuel treatments (360 years).

\subsection{Fuel treatment effects on forest $C$}

The forests of the LTB continued to sequester $C$ into the next century, regardless of fuel treatment or non-fuel treatment scenario (see also Loudermilk et al., 2013). Fuel treatment simulations resulted in up to $25 \%$ lower forest $\mathrm{C}$ density $\left(\mathrm{g} \mathrm{C} \mathrm{m}^{-2}\right)$ than simulations without fuel treatments, depending on year and treatment area (Fig. 4). Differences between RPs were only evident in the defense zone and extended WUI, where a 30 year RP was applied. This allowed for more forest regeneration and $C$ accumulation between treatments. Net $C$ gain - where $C$ from simulations with fuel treatment exceeded $C$ from simulations without fuel treatments - occurred towards the very end of the century ( $\sim$ year 2100). Similar results were found at the landscape level (Fig. 5), with opposing feedbacks from for example, high C loss ( $25 \%$, year $2060)$ in the defensible space and some $C$ gain ( $10 \%$, year 2100$)$ in the outside treatment area. The Long Term Urban Core scenario (Fig. S7) had a similar reductive effect on forest $\mathrm{C}$ storage as did continuous treatments on a 15 year rotation period at the management and landscape level.

The increase in area burned caused by the high fire regime reduced carbon storage potential by $20 \%$ by the end of the century

Table 3

Simulated fire rotation periods and mean and standard deviation of fire sizes and mean annual area burned at the LTB for all fuel treatment scenarios, and across five replicate 100 year simulations, using the base (contemporary) and high fire regime (HFR). RP: rotation period.

\begin{tabular}{lllll}
\hline Fuel treatment scenario & Fire rotation period (yrs.) & Mean fire size (ha) & Max fire size (ha) & Mean annual area burned (ha) \\
\hline No fuel treatments & 360 & $70(110)$ & $848(212)$ & $192(91)$ \\
Continuous - 15 year RP & 800 & $28(50)$ & $486(135)$ & $87(56)$ \\
Continuous - 30 year RP & 680 & $35(56)$ & $446(125)$ & $102(51)$ \\
Transition - 15 year RP & 720 & $34(58)$ & $418(95)$ & $98(53)$ \\
Transition - 30 year RP & 704 & $34(74)$ & $533(139)$ & $100(47)$ \\
Long term urban core & 510 & $46(74)$ & $610(145)$ & $137(66)$ \\
No fuel treatments - HFR & 188 & $60(99)$ & $950(102)$ & $369(136)$ \\
Continuous - 15 year RP - HRF & 367 & $33(60)$ & $599(185)$ & $206(90)$ \\
Continuous - 30 year RP - HRF & 310 & $37(67)$ & $652(188)$ & $255(91)$ \\
\hline
\end{tabular}

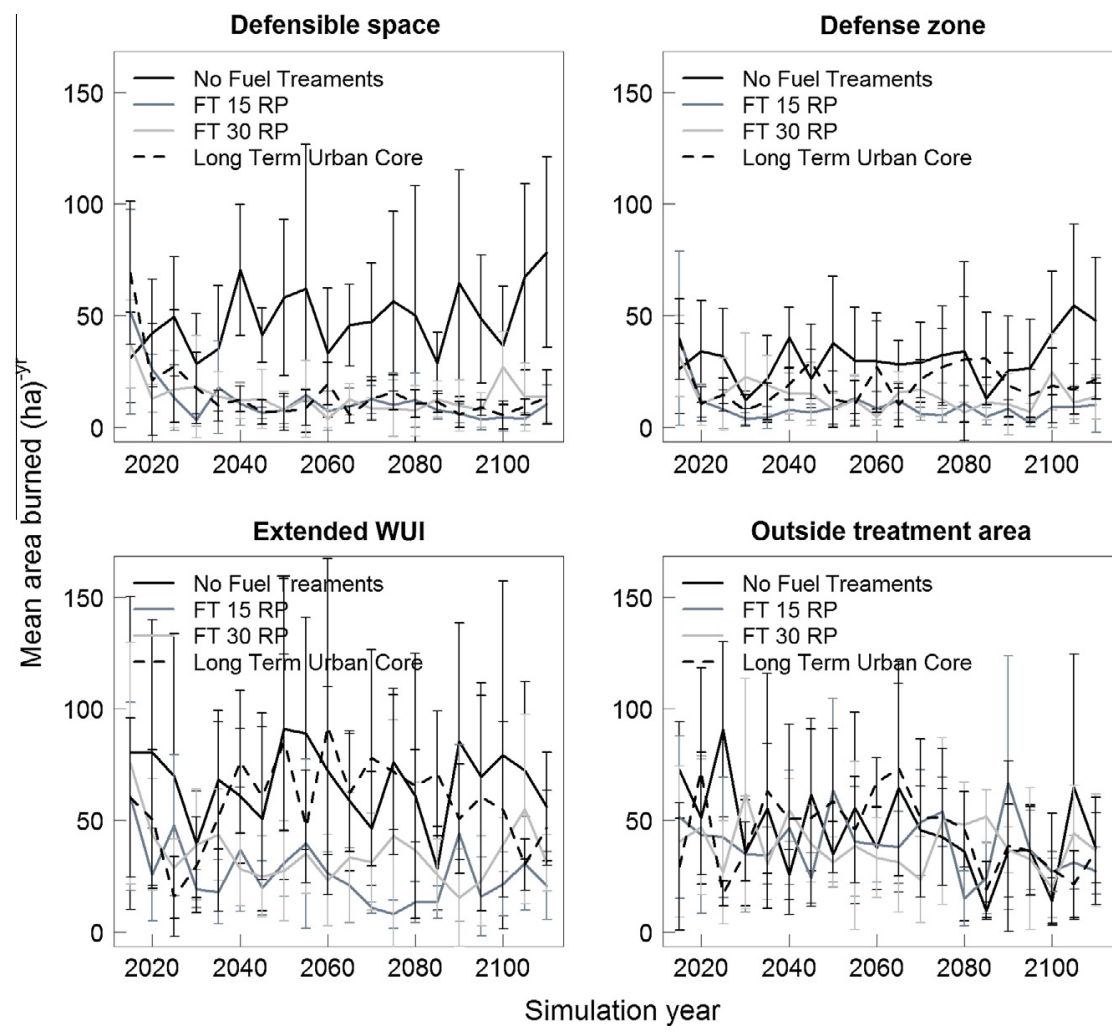

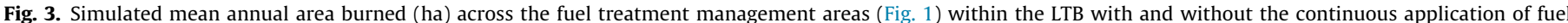

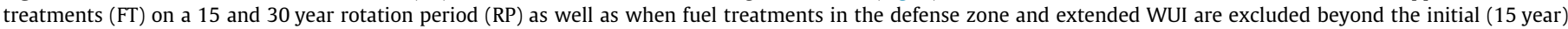
treatment period (Long Term Urban Core). This represents mean and standard error across five replicate simulations. 
in simulations without fuel treatments (Fig. 6). Fuel treatments reduced $\mathrm{C}$ similarly to the contemporary fire regime, although net $\mathrm{C}$ gain occurred after year 2080, 30 years earlier than the contemporary fire regime. There were no differences between the transition and continuous treatment scenarios on forest $C$.

\subsection{Fuel treatment effects on species}

Under a contemporary fire regime and no fuel treatments, white fir was dominant with up to $50 \%$ more mean aboveground live biomass than any other species (Fig. 7a). Continuous fuel treatments suppressed white fir by over $50 \%$ by the end of the century. Jeffrey pine responded positively to fuel treatments with more regeneration and became co-dominant with white fir by mid-century. By 2110 , forest composition was more characteristic of a mixed conifer system as reconstructed for pre-settlement LTB forests (Taylor, 2004), with higher proportions of red fir, lodgepole pine, and sugar pine (Fig. 7b). These changes in species composition are also evident within management areas where feedbacks between \% biomass removed, fuel treatment RP, and regeneration response created unique responses between species (Figs. S8 and S9).

The simulated high fire regime lowered aboveground live biomass of white fir, especially towards the end of the century, compared to the contemporary fire regime (Fig. 7c). Continuous fuel treatments suppressed white fir by over $30 \%$ by the end of the century (Fig. 7d). Jeffrey pine became the dominant tree species, with $12 \%$ more aboveground live biomass then white fir in year 2110. Similar to the contemporary fire regime, forest composition became more characteristic of a mixed conifer system with the implementation of fuel treatments. There were no differences between the transition and continuous treatment scenarios on species dynamics.

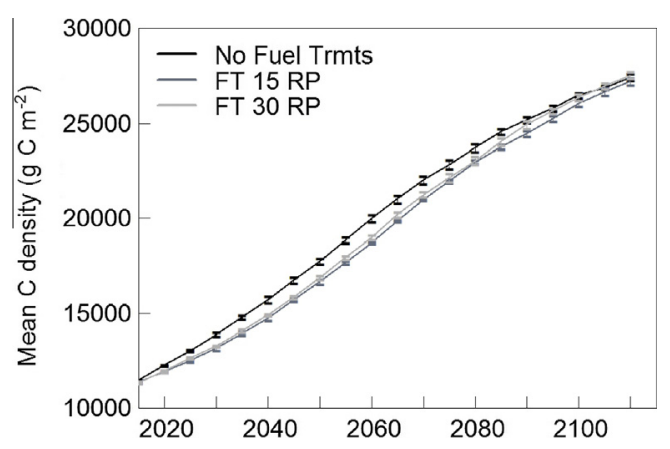

Fig. 5. Simulated mean landscape $C$ density $\left(\mathrm{g} \mathrm{C}^{2}\right.$, live $C+$ detrital $\left.C+S O C\right)$ with and without the continuous application of fuel treatments (FT) on a 15 and 30 year rotation period $(\mathrm{RP})$.

\section{Discussion}

This study highlights how the continuous application of fuel treatments may achieve multiple management objectives, including the reduction of wildfire risk and associated $C$ emissions and the creation of more diverse forest structure and composition. Targeting treatments within high ignitions areas reduced wildfire spread and intensity across the LTB landscape, regardless of simulated fire regime, fuel treatment type, or re-application interval. These treatments may come at a cost of $C$ removal that may take up to a century to recover, but may also depend on future wildfire activity. Fuel treatments may become more effective in a more active fire environment (e.g., high fire regime scenario), where wildfire and treatments are more likely to intersect. Similarly, net $C$ gain from fuel treatments is predicted to occur earlier in the next century under an intensified wildfire regime. However,

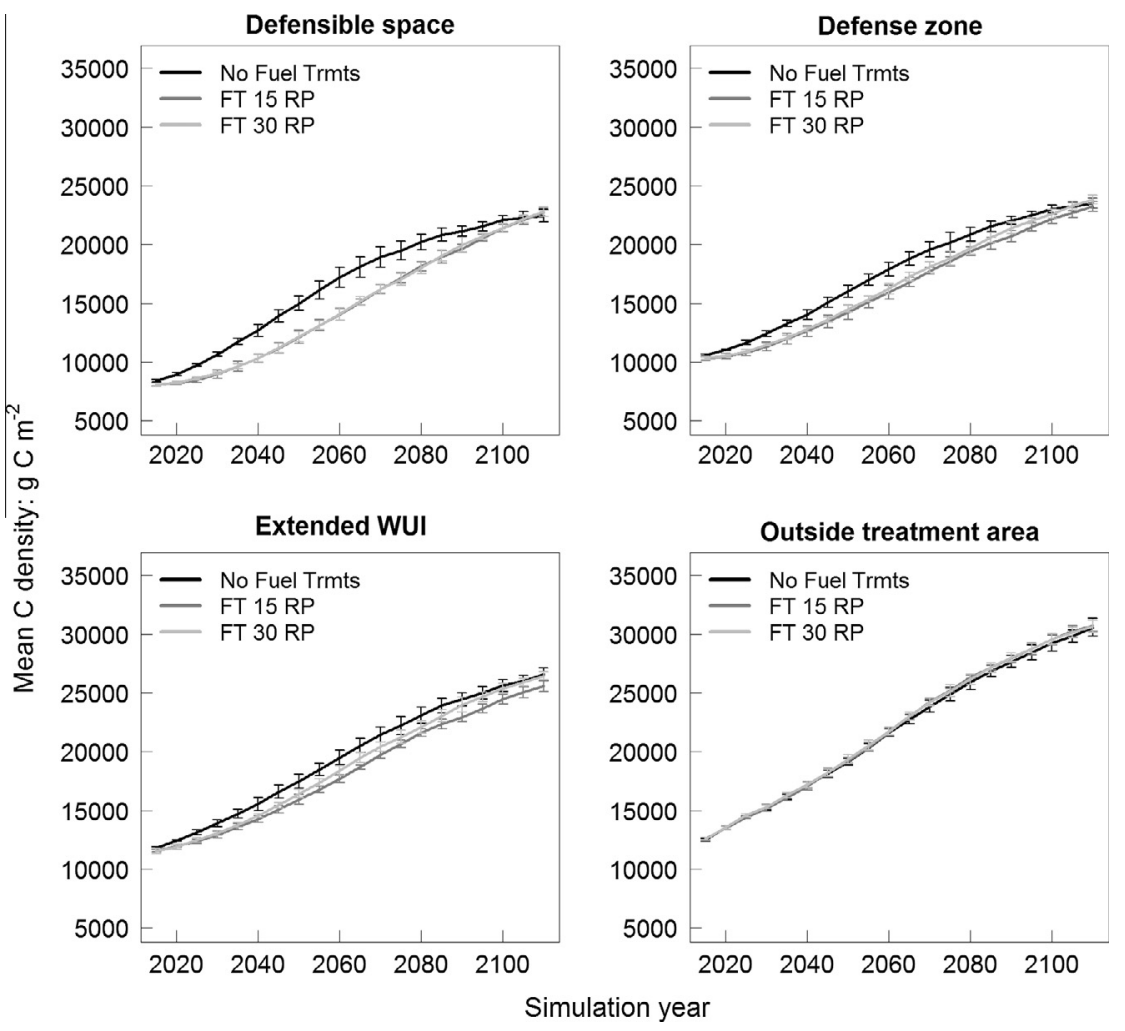

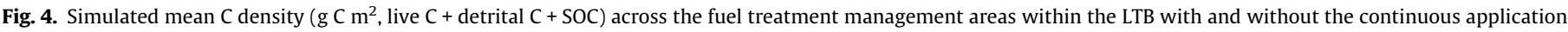
of fuel treatments (FT) on a 15 and 30 year rotation period (RP). 


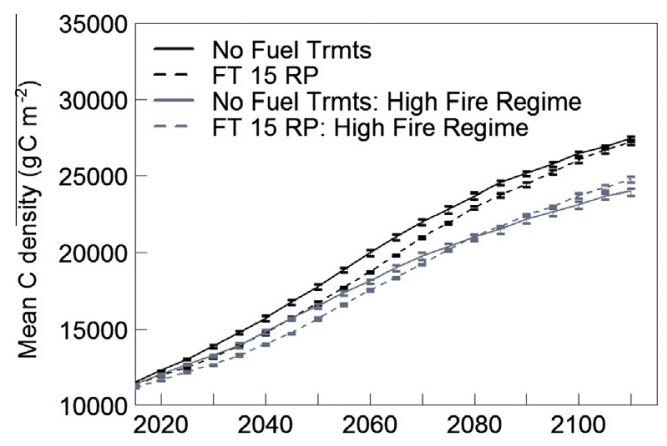

Fig. 6. Simulated mean landscape $C$ density $\left(\mathrm{g} \mathrm{C}^{2}\right.$, live $C+$ detrital $\left.C+S O C\right)$ using the contemporary fire regime and high fire regime, with and without the continuous application of fuel treatments (FT) on a 15 year rotation period (RP).

the forest of the LTB may remain a C sink regardless of treatments or simulated fire regime, at least over the next century, as a result of the landscape legacy of historic logging (Loudermilk et al., 2013). Subsequent research is examining whether and how much of a $\mathrm{C}$ sink the basin remains after consideration of climate change and bark beetle outbreaks. This study also illustrated how fuel treatments may facilitate shifts in dominance away from fire-susceptible tree species (e.g., white fir and incense cedar) to a higher proportion of fire-tolerant tree species (e.g., Jeffrey and sugar pine) and reduced densities of younger cohorts. A century of continuous fuel treatment applications altered forest tree species composition to one which is more representative of the historic mixed conifer system.

\subsection{Long-term landscape implementation of fuel treatments}

In the urbanized areas of the LTB, where high wildfire risk conditions prevail, the continuous application of fuel reduction treatments may be essential in reducing wildfire spread and intensity and controlling $\mathrm{C}$ emissions from wildfire into the coming century. We found that treatment placement may be of equal or greater importance than treatment type or re-application interval. All treatment types significantly reduced fire spread potential compared to non-treated areas, in part because simulated treatments were continuously applied in each time step (for either 15 or 30 year RP) and targeted in higher ignition areas within the WUI. The differences among treatment prescriptions were minimal at the scale modeled under the continuous application. Our simulations suggest that if fuel treatments were strategically placed over long time periods, the overall effect on mitigating wildfires may overshadow the underlying differences between prescription types at the landscape level. This has been found in other studies where a strategic placement was critical (Finney et al., 2008; Schmidt et al., 2008), and where prescription types or intensities (moderate vs. light thinning) had more local scale effects (Schmidt et al., 2008; Symons et al., 2008; Safford et al., 2009).

The significance of strategic placement was demonstrated through our simulated Long-Term Urban Core scenario. Under all scenarios we simulated an initial round of treatments over the first 15 years that resulted in treating approximately $25 \%$ of the forested land in the LTB. By confining subsequent treatments to the area of the LTB with the highest ignition densities (Loudermilk et al., 2012) and lowest elevation, area burned in the adjacent defense zone was reduced (Fig. 3), causing a residual
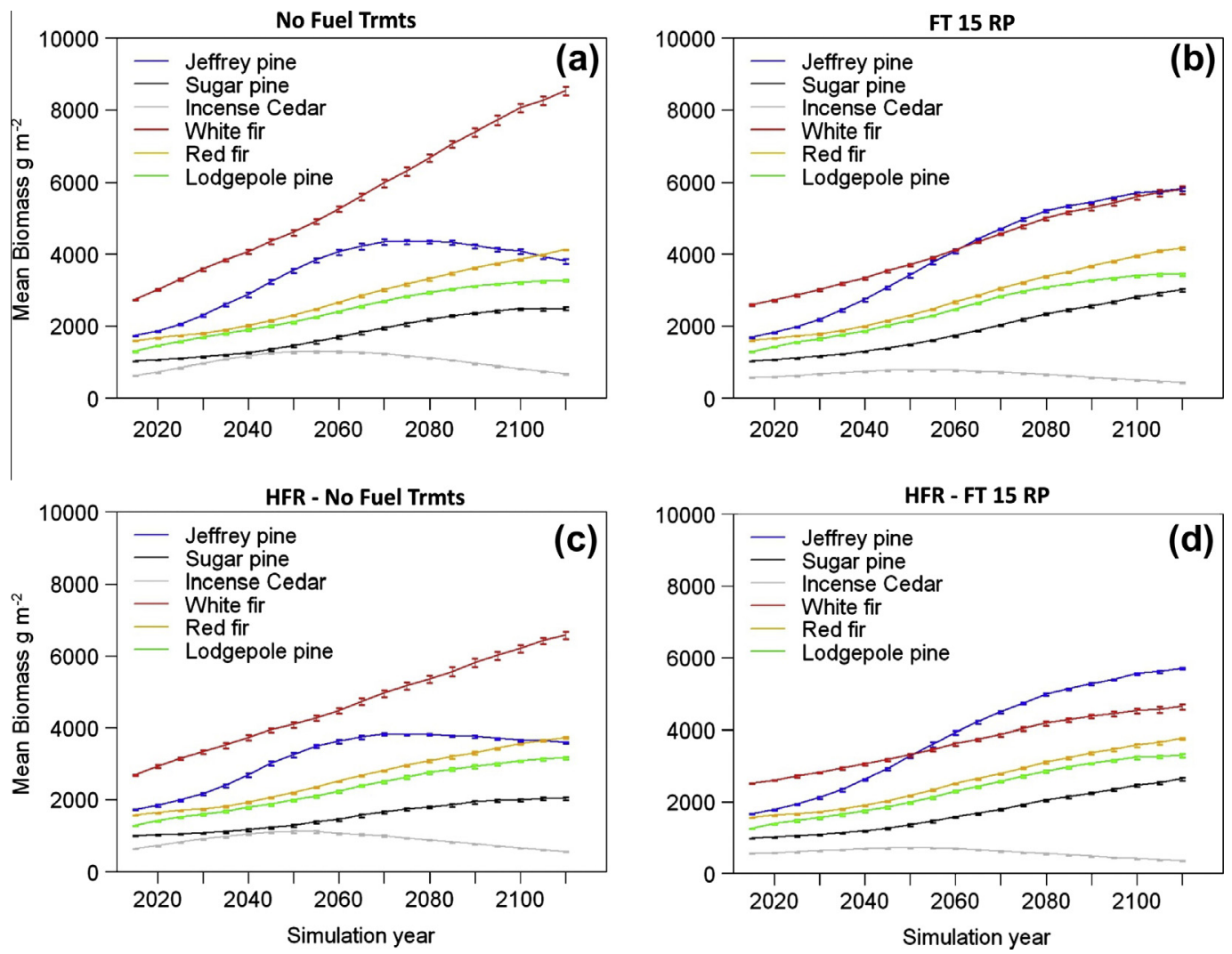

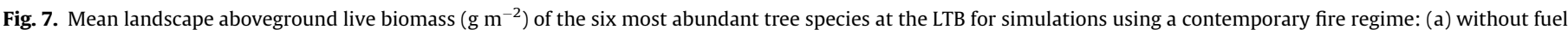

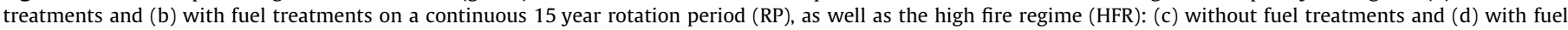
treatments on a continuous 15 year RP. 
effect of a smaller mean area burned across the entire landscape (Table 3). This lends support to the management tactic of concentrating resources in the most densely populated areas where fires are most likely to start. However, treatments had little effect on mitigating wildfires where treatments were not continuously applied, especially the extended WUI and outside treatment area (Fig. 3). Area burned and severity was not reduced in these areas because there were no long-term structural changes to the forest. Within 15-20 years, fuel loads were high again and younger cohorts had established creating more ladder fuels. Coupled with steeper slopes in these areas, fire spread rates were once again high.

Differences in the effectiveness of fuel treatments between the contemporary fire regime and a simulated intensified 'high' fire regime (Figs. 6 and 7) illustrated how fuel treatments may become more critical in a more wildfire prone future (Reinhardt et al., 2008). Without fuel treatments, the high fire regime almost doubled the mean annual area burned compared to the contemporary fire regime (Table 3). Continuous fuel treatments applied on a 15 year RP cut the FRP in half under both fire regimes, with similar results for the 30 year RP. However, the resulting FRP with either $\mathrm{RP}$ (367 or 310 years for the 15 and $30 \mathrm{RP}$, respectively) under the high fire regime was similar to that of the contemporary fire regime with no fuel treatments (360 year FRP), suggesting that the amount of area treated will become more important as the number of wildfires increase. As such, shorter rotation periods may become more necessary in the future. Our results agree with projections that suggest more wildfire ignitions (Parisien et al., 2012) along with more severe fires (Westerling et al., 2006) are more likely in a warming climate. Applying treatments at a scale that enables wildfire to intersect treatments more often may be vital to the future LTB forests and protecting the surrounding human community.

While reducing wildfire risk is the primary goal in the populated LTB, implementing fuel treatments that create a more fireresilient forest and restore the compositional and structural integrity of the forest (Reinhardt et al., 2008; Hurteau and North, 2009) are important secondary goals. In our study, fuel treatments were especially effective in altering forest composition and species dominance patterns, particularly between well established and competing species (Fig. 7 and see Loudermilk et al., 2012). Our prescriptions targeted stands with higher proportions of younger age-cohorts and were designed to favor establishment of more fire-tolerant, shade-sensitive species. Fuel treatments preferentially targeted white fir and incense cedar and allowed the release of Jeffrey pine, sugar pine, and red fir. In the longrun, a more diverse mixed-conifer system was created, where Jeffrey pine and white fir shared dominance and other species were more evenly represented on the landscape. Jeffrey pine became the dominant species only when coupled effects of more fire activity (high fire regime) and continuous fuel treatments were simulated (Fig. 7d). A 15 year RP suppressed biomass accumulation of white fir earlier in the century, and to a greater degree, than did the $30 \mathrm{RP}$ (Fig. S8). In contrast, more frequent treatment (15 yr RP) allowed for a greater accumulation of Jeffrey Pine biomass by the end of the century (Fig. S9). The 30 year rotation period scenario in the extended WUI resulted in $40 \%$ higher mean landscape white fir biomass than the 15 year rotation in year 2100 , indicating that more frequent treatment is needed to suppress the regeneration of this fast growing, prolific seeder (Laacke, 1990). While the longer rotation period had little long term effect on wildfire risk, such changes in forest composition are important for LTB managers for addressing the imbalances that can be created by logging and fire suppression and achieving goals for restoring the forest to a more fire-resilient, historic-like condition.

\subsection{Potential net $C$ gain and trade-offs}

The LTB may continue to sequester forest $C$ into the next century (Loudermilk et al., 2013) regardless of fuel treatment strategy or fire regime. This is mainly an artifact of the Comstock Era, where nearly $70 \%$ of the area was clear-cut in the late 19th century (e.g., Taylor, 2004) and was left to self-regenerate and is therefore still relatively young with considerable growth potential remaining. Under such conditions, the implementation of fuel treatments may result in both short and long-term tradeoffs. Over the near future, more forest $\mathrm{C}$ would be removed from the system than would be released without treatment (i.e., from ecosystem respiration); creating a net C 'cost' (Mitchell et al., 2009; Campbell et al., 2012). The $C$ loss, however, occurs in the younger cohorts targeted by the treatments. This results in a reduction in ladder fuels and fire spread potential that mitigates wildfire risk by reducing average fire size and total area burned if treatments are strategically placed, notwithstanding the positive ecosystem effects (Hurteau and North, 2009; Stephens et al., 2012a). If the fire regime (e.g., $\sim 360$ FRP) and climate remain similar to contemporary conditions (i.e., climate does not warm), a net gain in C could take up to a century with ongoing fuel treatments. Eventually, reduced fire severity and enhanced forest re-growth would lead to a net gain in $\mathrm{C}$ storage at the management area and landscape level.

Although fuel treatments had short-term effects on area burned, they had longer-term effects on $C$ sequestration. After simulated cohorts were reduced or removed, there was a lag in forest response. This included regeneration and growth response of the remaining cohorts, as well as changes in successional patterns and $C$ storage levels. Interestingly, the Long Term Urban Core scenario was as effective at storing $C$ with minimal treatment over time, compared to the continuous treatments (Fig. S7).

Our simulations indicated that treatment effectiveness in managing for C stocks may be inextricably linked to future wildfire activity. If wildfire activity continues to increase as in recent decades (Westerling et al., 2006), then fuel treatments may become more effective and compulsory in the long run. Net $C$ gain could occur decades earlier (e.g., high fire regime, Fig. 6) than suggested by a more contemporary - and likely conservative - fire regime. Balancing the demand to maximize $C$ sequestration, while managing for wildfire risk, forest resiliency, other societal tradeoffs becomes more difficult, yet critical in the predicted wildfire regimes of the future (Mitchell et al., 2009).

\subsection{Implications for landscape management}

This study supports the use of fuel treatments in the LTB as a necessary tool in reducing landscape level wildfire risk and managing long-term forest $\mathrm{C}$. Our simulated fuel treatments returned the forest to more historic and fire resilient conditions, reduced wildfire risk and severity, controlled wildfire $C$ emissions, and in the long run resulted in a net $C$ gain. These positive outcomes far outweigh the intermediary loss in forest $C$ from biomass removal, especially faced with the latent increase in human-caused and climate driven fire activity. In addition, although we did not conduct a full life cycle analysis, if the young trees removed were substitutions for fossil fuels burning (e.g., through heating or electricity generation) then the net reduction in $C$ emissions could be slightly higher (Campbell et al., 2012).

Our case study of fuel reduction treatments in the LTB focused on a relatively small and unique landscape that has considerable environmental protections and funding for forest management. Following the Lake Tahoe Basin Multi-Jurisdictional Fuel Reduction and Wildfire Prevention Strategy (Marlow et al., 2007), our simulated fuel treatment scenarios included an initial round of treatments (first 15 years) in a quarter of the forested landscape, 
targeted in lower elevation areas (near urban areas around the lake shore) that are at high risk for wildfires. As such, the residual effects observed from the minimal treatment scenario of only treating the Urban Core through time lends support to the management approach of prioritizing treatments in the most densely populated areas where fires are most likely to start. This may not be feasible in other forests, where urban areas are more sparsely configured and elevation gradients and forest conditions are more complex.

Our study suggests that at the landscape-scale, rotation period is not as critical as fuel treatment placement, but understanding treatment effectiveness at the stand scale and how to best schedule re-entry treatments is a high priority management concern. We found that wildfire frequency and size minimized the discrepancies between the 15 and 30 year rotation period at the landscape scale. Mean simulated fire size without fuel treatment was relatively small (70 ha) compared to typical western wildfires. This is because most fires that start at Lake Tahoe are quickly suppressed, so the average fire size in the calibration dataset (1995-2007) was relatively small, with only four fires larger than 100 ha. Despite similar area burned with either fuel treatment RP, the 15 year RP generated more favorable changes in species composition earlier in the century than did the 30 year RP. The 15 year RP was therefore more effective in meeting management objectives at the stand scale for creating a more fire resilient forest, suppressing white fir, and diminishing the effects of past logging and fire suppression. Managers are faced with weighing the benefits of shorter rotation period against the greater $C$ accumulation afforded by the longer rotation period.

Differences in outcomes between rotation periods and implementation scenarios have significant cost implications. Treating on a 30 year RP rather than a 15 year RP would lead to significant savings in any managed system. Recent recommendations for forest restoration in the Sierra Nevada call for increased use of prescribed burning, within and between treated areas, to reduce the need for perpetual thinning and to reduce costs (North et al., 2009; Stephens et al., 2012b) may be a better option than continuous fuel treatments in the long-run. However, the ability to follow up thinning treatments with prescribed fire in the LTB is limited due to strict environmental regulation aimed at protecting the clarity of Lake Tahoe. Our model demonstrated that a small amount of wildfire on the landscape resulted in significant changes in the $\mathrm{C}$ pool, and that strategically placed fuel treatments substantially reduced wildfire risk, increased fire resiliency of the forest, and is beneficial for long-term C management.

\section{Acknowledgements}

We would like to thank all of the Lake Tahoe Basin agency personnel at the federal, state, and local level who participated in two workshops to help us develop fuel treatment strategies that represent the current and anticipated management activity in the region. We thank the Tahoe Regional Planning Agency and the Tahoe Center for Environmental Studies for hosting the workshops. We would especially like to thank Tiffany Van Huysen of the USDA Forest Service Pacific Southwest Research Station for her support, administration of the grant, and participation in the agency workshops. We obtained many insights and a valuable GIS database from Dave Fournier and Kurt Teuber (USDA Forest Service, Lake Tahoe Basin Management Unit). Sarah Karam (University of Nevada-Reno, UNR) provided many input model parameters associated with species life history and physiological attributes. This research was supported using funds provided by the Bureau of Land Management through the sale of public lands as authorized by the Southern Nevada Public Land Management Act (SNPLMA), and was funded in part through grant 10 DG-11272170-038 from the USDA Forest Service Pacific Southwest Research Station. We thank Portland State University (PSU) and UNR for their administrative support. The research team of the Dynamic Ecosystems and Landscapes Lab, PSU was especially important for the success of this project. The views in this manuscript are those of the authors and do not necessary reflect those of the USDA Forest Service Pacific Southwest Research Station or Bureau of Land Management.

\section{Appendix A. Supplementary material}

Supplementary data associated with this article can be found, in the online version, at http://dx.doi.org/10.1016/j.foreco.2014.03. 011.

\section{References}

Agee, J.K., Skinner, C.N., 2005. Basic principles of forest fuel reduction treatments For. Ecol. Manage. 211, 83-96.

Barbour, M., Kelley, E., Maloney, P., Rizzo, D., Royce, E., Fites-Kaufmann, J., 2002. Present and past old-growth forests of the Lake Tahoe Basin, Sierra Nevada, US. J. Veg. Sci. 13, 461-472

Brown, R.T., Agee, J.K., Franklin, J.F., 2004. Forest restoration and fire: principles in the context of place. Conserv. Biol. 18, 903-912.

Beaty, R.M., Taylor, A.H., 2008. Fire history and the structure and dynamics of a mixed conifer forest landscape in the northern Sierra Nevada, Lake Tahoe Basin, California, USA. For. Ecol. Manage. 255, 707-719.

Calkin, D., Gebert, K., 2006. Modeling fuel treatment costs on forest service lands in the Western United States. Western J. Appl. For. 21, 217-221.

Campbell, J., Harmon, M.E., Mitchell, S.R., 2012. Can fuel-reduction treatments really increase forest carbon storage in the western US by reducing future fire emissions? Front. Ecol. Environ. 10, 83-90.

Collins, B.M., Stephens, S.L., Moghaddas, J.J., Battles, J., 2010. Challenges and approaches in planning fuel treatments across fire-excluded forested landscapes. J. For. 108, 24-31.

Daugherty, P.J., Fried, J.S., 2007. Jointly optimizing selection of fuel treatments and siting of forest biomass-based energy production facilities for landscape-scale fire hazard reduction. INFOR: Inform. Syst. Operat. Res. 45, 17-30.

Finkral, A.J., Evans, A.M., 2008. Effects of a thinning treatment on carbon stocks in a northern Arizona ponderosa pine forest. For. Ecol. Manage. 255, 2743-2750.

Finney, M.A., Seli, R.C., McHugh, C.W., Ager, A.A., Bahro, B., Agee, J.K., 2008 Simulation of long-term landscape-level fuel treatment effects on large wildfires. Int. J. Wildland Fire 16, 712-727.

Gustafson, E.J., Shifley, S.R., Mladenoff, D.J., Nimerfro, K.K., He, H.S., 2000. Spatial simulation of forest succession and timber harvesting using LANDIS. Can. J. For. Res. 30, 32-43.

Hurteau, M., North, M., 2009. Fuel treatment effects on tree-based forest carbon storage and emissions under modeled wildfire scenarios. Front. Ecol. Environ. 7, 409-414.

Hurteau, M.D., Koch, G.W., Hungate, B.A., 2008. Carbon protection and fire risk reduction: toward a full accounting of forest carbon offsets. Front. Ecol. Environ. 6, 493-498.

Johnson, D.W., Susfalk, R.B., Dahlgren, R.A., 1997. Nutrient fluxes in forests of the eastern Sierra Nevada Mountains, United States of America. Global Biogeochem. Cycles 11, 673-681.

Karam, S.L., Weisberg, P.J., Scheller, R.M., Johnson, D.W., Miller, W., 2013. Development and evaluation of a nutrient cycling extension for the LANDIS-Il landscape simulation model. Ecol. Model. 250, 45-57.

Laacke, R.J., 1990. Abies concolor (Gord. \& Glend.) Lindl. ex Hildebr. White fir. In: Burns, R.M., B.H.H.T. (Eds.), Silvics of North America: 1: Conifers. Agriculture Handbook 654. USDA Forest Service, Washington, D.C., pp. 36-46.

Littell, J.S., McKenzie, D., Peterson, D.L., Westerling, A.L., 2009. Climate and wildfire area burned in western U.S. ecoprovinces, 1916-2003. Ecol. Appl. 19, $1003-$ 1021.

Loudermilk, E.L., Stanton, A.E., Scheller, R.M., Weisberg, P.J., Yang, J., Dilts, T.E. Skinner, C., 2012. Final Report: Management Options for Reducing Wildfire Risk and Maximizing Carbon Storage under Future Climate Changes, Ignition Patterns, and Forest Treatments. Pacific Southwest Research Station, Tahoe Center for Environmental Studies, Incline Village, NV, p. 100.

Loudermilk, E.L., Scheller, R.M., Weisberg, P.J., Yang, J., Dilts, T.E., Karam, S.L. Skinner, C., 2013. Carbon dynamics in the future forest: the importance of longterm successional legacy and climate-fire interactions. Glob. Change Biol. 19, 3502-3515.

Maloney, P.E., Vogler, D.R., Eckert, A.J., Jensen, C.E., Neale, D.B., 2011. Population biology of sugar pine (Pinus lambertiana Dougl.) with reference to historical disturbances in the Lake Tahoe Basin: implications for restoration. For. Ecol. Manage. 262, 770-779.

Marlow, D., French, C., Graham, W., Hall, R., Howle, S., Whisenn, K., York, J., Taylor M., Holl, S., Teuber, K., 2007. Lake Tahoe Basin: Multi-Jurisdictional Fuel Reduction and Wildfire Prevention Strategy 10 Year Plan. Lake Thaoe Basin Management Unit, South Lake Tahoe, CA, p. 80. 
Miranda, B.R., Sturtevant, B.R., Stewart, S.I., Hammer, R.B., 2012. Spatial and temporal drivers of wildfire occurrence in the context of rural development in northern Wisconsin, USA. Int. J. Wildland Fire 21, 141-154.

Mitchell, S.R., Harmon, M.E., O'Connell, K.E.B., 2009. Forest fuel reduction alters fire severity and long-term carbon storage in three Pacific Northwest ecosystems. Ecol. Appl. 19, 643-655.

Murphy, J.D., Johnson, D.W., Miller, W.W., Walker, R.F., Blank, R.R., 2006. Prescribed fire effects on forest floor and soil nutrients in a Sierra Nevada Forest. Soil Sci. 171 (181-199), 1. http://dx.doi.org/10.1097/1001.ss.0000193886.0000135336. d0000193888.

Nagel, T.A., Taylor, A.H., 2005. Fire and persistence of montane chaparral in mixed conifer forest landscapes in the Northern Sierra Nevada, Lake Tahoe Basin, California, USA. J. Torrey Botanical Soc. 132, 442-457.

Nave, L.E., Vance, E.D., Swanston, C.W., Curtis, P.S., 2010. Harvest impacts on soil carbon storage in temperate forests. For. Ecol. Manage. 259, 857-866.

North, M.P., Hurteau, M.D., 2011. High-severity wildfire effects on carbon stocks and emissions in fuels treated and untreated forest. For. Ecol. Manage. 261, 1115-1120.

North, M., Stine, P., O'Hara, K., Zielinski, W., Stephens, S., 2009. An Ecosystem Management Strategy for Sierran Mixed-Conifer Forests. United States Department of Agriculture, Forest Service, Pacific Southwest Research Station, Albany, CA, p. 49.

Ottmar, R., Safford, H., 2011. Final Report: FCCS Fuelbeds for the Lake Tahoe Basin Management Unit. Pacific Southwest Research Station, Tahoe Center for Environmental Studies, Incline Village, NV, p. 27.

Parisien, M-A., Snetsinger, S, Greenberg JA, Nelson, CR. Schoennagel, T Dobrowski, S.Z., Moritz, M.A., 2012. Spatial variability in wildfire probability across the western United States. Int. J. Wildland Fire 21, 313-327.

Parsons, D.J., DeBenedetti, S.H., 1979. Impact of fire suppression on a mixed-conifer forest. For. Ecol. Manage. 2, 21-33.

Parton, W.J., Anderson, D.W., Cole, C.V., Stewart, J.W.B., 1983. Simulation of soil organic matter formation and mineralization in semiarid agroecosystems. In: Lowrance, R.R., Todd, R.L., Asmussen, L.E., Leonard, R.A. (Eds.), Nutrient Cycling in Agricultural Ecosystems. The University of Georgia, College of Agriculture Experimental Stations, Athens, Georgia, pp. 533-550.

Pilliod, D.S., Bull, E.L., Hayes, J.L., Wales, B.C., 2006. Wildlife and Invertebrate Response to Fuel Reduction Treatments in Dry Coniferous Forests of the Western United States: A Synthesis. Rocky Mountain Research Station, USDA Forest Service Fort Collins CO.

Radeloff, V.C., Hammer, R.B., Stewart, S.I., Fried, J.S., Holcomb, S.S., McKeefry, J.F. 2005. The wildland-urban interface in the United States. Ecol. Appl. 15, 799_ 805.

Reinhardt, E.D., Cohen, J.D., Calkin, D.E., Keane, R.E., 2008. Objectives and considerations for wildland fuel treatment in forested ecosystems of the interior western United States. For. Ecol. Manage. 256, 1997-2006.

Rhodes, J.J., Baker, W.L., 2008. Fire probability, fuel treatment effectiveness and ecological tradeoffs in western US public forests. Open For. Sci. J. 1, 1-7.

Rogers, J.H., 1974. Soil survey Tahoe Basin Area: California and Nevada. U.S Department of Agriculture, Soil Conservation Service, Washington, D.C.

Safford, H.D., Schmidt, D.A., Carlson, C.H., 2009. Effects of fuel treatments on fire severity in an area of wildland-urban interface, Angora Fire, Lake Tahoe Basin, California. For. Ecol. Manage. 258, 773-787.
Scheller, R.M., Domingo, J.B., Sturtevant, B.R., Williams, J.S., Rudy, A., Gustafson, E.J., Mladenoff, D.J., 2007. Design, development, and application of LANDIS-II, a spatial landscape simulation model with flexible temporal and spatial resolution. Ecol. Model. 201, 409-419.

Scheller, R.M., Hua, D., Bolstad, P.V., Birdsey, R.A., Mladenoff, D.J., 2011a. The effects of forest harvest intensity in combination with wind disturbance on carbon dynamics in Lake States Mesic Forests. Ecol. Model. 222, 144-153.

Scheller, R.M., Spencer, W., Rustigian-Romsos, H., Syphard, A., Ward, B., Strittholt, J., 2011b. Using stochastic simulation to evaluate competing risks of wildfires and fuels management on an isolated forest carnivore. Landscape Ecol. 26, 14911504.

Scheller, R.M., Van Tuyl, S., Clark, K., Hom, J., La Puma, I., 2011c. Carbon sequestration in the New Jersey pine barrens under different scenarios of fire management. Ecosystems 14, 987-1004.

Schmidt, D.A., Skinner, C.N., Taylor, A.H., 2008. The influence of fuels treatment and landscape arrangement on simulated fire behavior, Southern Cascade range, California. For. Ecol. Manage. 255, 3170-3184.

Schwilk, D.W., Skinner, C.N., Outcalt, K.W., Moghaddas, J.J., Stephens, S.L., Youngblood, A., Yaussy, D.A., Waldrop, T.A., Mclver, J., Knapp, E.E., Keeley, J.E. Bailey, J.D., Harrod, R.J., Fiedler, C.E., Fettig, C.J., 2009. The national fire and fire surrogate study: effects of fuel reduction methods on forest vegetation structure and fuels. Ecol. Appl.: Publ. Ecol. Soc. Am. 19, 285-304.

Stephens, S.L., Boerner, R.E., Moghaddas, J.J., Moghaddas, E.E., Collins, B.M., Dow, C.B., Edminster, C., Fiedler, C.E., Fry, D.L., Hartsough, B.R., 2012a. Fuel treatment impacts on estimated wildfire carbon loss from forests in Montana, Oregon, California, and Arizona. Ecosphere 3, art38.

Stephens, S.L., Collins, B.M., Roller, G., 2012b. Fuel treatment longevity in a Sierra Nevada mixed conifer forest. For. Ecol. Manage. 285, 204-212.

Sturtevant, B.R., Scheller, R.M., Miranda, B.R., Shinneman, D., Syphard, A., 2009. Simulating dynamic and mixed-severity fire regimes: a process-based fire extension for LANDIS-II. Ecol. Model. 220, 3380-3393.

Symons, J.N., Fairbanks, D.H., Skinner, C.N., 2008. Influences of stand structure and fuel treatments on wildfire severity at Blacks Mountain Experimental Forest, northeastern California. The California Geographer 48, 61-82.

Syphard, A.D., Radeloff, V.C., Keeley, J.E., Hawbaker, T.J., Clayton, M.K., Stewart, S.I., Hammer, R.B., 2007. Human influence on California fire regimes. Ecol. Appl. 17, 1388-1402.

Syphard, A.D., Scheller, R.M., Ward, B.C., Spencer, W.D., Strittholt, J.R., 2011. Simulating landscape-scale effects of fuels treatments in the Sierra Nevada, California, USA. Int. J. Wildland Fire 20, 364-383.

Taylor, A.H., 2004. Identifying forest reference conditions on early cut-over lands, Lake Tahoe Basin, USA. Ecol. Appl. 14, 1903-1920.

Thompson, M.P., Vaillant, N.M., Haas, J.R., Gebert, K.M., Stockmann, K.D., 2013. Quantifying the potential impacts of fuel treatments on wildfire suppression costs. J. For. 111, 49-58.

Westerling, A.L., Hidalgo, H.G., Cayan, D.R., Swetnam, T.W., 2006. Warming and earlier spring increase western U.S. Forest Wildfire Activity. Science 313, $940-$ 943.

Yang, J., He, H.S., Shifley, S.R., Gustafson, E.J., 2007. Spatial patterns of modern period human-caused fire occurrence in the Missouri Ozark Highlands. For. Sci. $53,1-15$. 